\title{
Audição de vozes em população adulta não psiquiátrica: revisão integrativa da literatura
}

\author{
Luana Ribeiro Borges* \\ Luciane Prado Kantorski** \\ Suele Manjourany Silva Duro*** \\ Maria Laura de Oliveira Couto**** \\ Thylia Teixeira Soura***** \\ Liamara Denise Ubessi******
}

\begin{abstract}
Resumo
Este estudo é uma revisão integrativa da literatura, que analisou a produção científica acerca da audição de vozes e os fatores relacionados em população adulta não psiquiátrica. Incluiu artigos originais publicados até 2018 nas bases de dados eletrônicas: Sci-Verse Scopus; Web of Science; PubMed e LILACS. Adotaram-se os termos: "voice hearing" OR “voice hearer" OR “voice hearers" OR "hearing voices” como estratégia de busca, resgatando-se 1029 títulos. Identificaram-se 44 artigos para leitura na íntegra, 18 preencheram os critérios para inclusão. Evidências disponíveis mostraram uma variação de 0,8 a $41 \%$ de audição de vozes em populações não psiquiátricas. Observou-se que a audição de vozes, assim como outras experiências reconhecidas como psicóticas são vivenciadas por muitas pessoas, com intensidades, frequências e repercussões diferentes na vida de cada uma. Níveis de ansiedade, depressão e trauma na infância, em especial abuso sexual, têm sido discutidos como potenciais fatores relacionados. A presença marcante na literatura do fator traumático como preditor dessas experiências ressalta a necessidade, e evidencia a urgência da superação dos enquadramentos sintomáticos para construção de explicações mais individualizadas para o fenômeno de acolhimento e escuta das histórias de vida em sua singularidade. Além disso, possibilita vislumbrar ações precoces para prevenção de trauma na infância como possível intervenção protetora.
\end{abstract}

Palavras-chave: Saúde mental; Alucinações; Fatores Epidemiológicos.

* ORCID iD http://orcid.org/0000-0002-9772-5969 . URL https://orcid.org/0000-0002-9772-5969. Instituição/Afiliação Universidade Federal de Pelotas (UFPEL). Mestre em Saúde Coletiva (UNICAMP). Professora Assistente do curso de Enfermagem da Universidade Federal do Pampa (UNIPAMPA). Doutoranda do Programa de Pós-graduação de Enfermagem da Universidade Federal de Pelotas (UFPel).

** ORCID iD http://orcid.org/0000-0001-9726-3162 . URL http://orcid.org/0000-0001-9726-3162. Universidade Federal de Pelotas (UFPEL). Doutora em Enfermagem (USP - Ribeirão Preto), Brasil. Professora Titular da Faculdade de Enfermagem da Universidade Federal de Pelotas.

*** ORCID iD http://orcid.org/0000-0001-5730-0811 . URL http://orcid.org/0000-0001-5730-0811. Universidade Federal de Pelotas (UFPEL). Doutora em Epidemiologia (UFPEL). Professora Adjunta A da Faculdade de Enfermagem da Universidade Federal de Pelotas.

**** ORCID iD http://orcid.org/0000-0002-5103-3000 . URL http://orcid.org/0000-0002-5103-3000. Universidade Federal de Pelotas (UFPEL). Psicóloga graduada pela Universidade Federal de Pelotas (UFPel); Mestre em Ciências pelo Programa de Pós-Graduação em Enfermagem da (UFPel); Doutoranda no Programa de Pós-Graduação em Enfermagem da (UFPel).

***** ORCID iD http://orcid.org/0000-0002-7086-0853. URL https://orcid.org/0000-0002-7086-0853. Universidade do Vale do Rio dos Sinos (UNISINOS). Enfermeira. Mestre em Ciências pelo Programa de Pós-Graduação em Enfermagem da Universidade Federal de Pelotas (UFPel). Residente em Saúde Mental pela Universidade do Vale do Rio dos Sinos (UNISINOS).

***** ORCID iD http://orcid.org/0000-0002-5884-9969. URL https://orcid.org/0000-0002-5884-9969. Universidade Federal de Pelotas (UFPEL). Psicóloga e Enfermeira pela Universidade Regional do Noroeste do Estado do Rio Grande do Sul (UNIJUI). Especialista em Gestão de Sistema e Equipes de Saúde, Gerontologia e Saúde Pública. Mestre em Educação nas Ciências pela Universidade Regional do Noroeste do Estado do Rio Grande do Sul (UNIJUI). Doutora e Pós-doutoranda no PPG em Enfermagem da Universidade Federal de Pelotas (UFPel). Graduanda em Filosofia pela Universidade Federal de Pelotas (UFPel). 


\title{
Hearing of voices in a non-psychiatric adult population: an integrative literature review
}

\begin{abstract}
This study is an integrative literature review that analyzes the scientific production on the hearing of voices and related factors in the adult non-psychiatric population. It included original articles published until 2018 in the electronic databases: Sci-Verse Scopus; Web of Science; PubMed e LILACS. The terms "voice hearing" OR "voice hearer" OR "voice hearers" OR "hearing voices" were adopted as a search strategy, resulting in 1029 titles. Forty-four articles were identified for full reading, 18 fulfilled the inclusion criteria. Available evidence has shown a range of 0.8 to $41 \%$ of voice hearing in non-psychiatric populations. It was observed that the hearing of voices, as well as other experiences recognized as psychotic, are lived by many people, with different intensities, frequencies and repercussions in each person's life. Levels of anxiety, depression and trauma in childhood, in particular sexual abuse, have been discussed as potential related factors. The marked presence in the literature of the traumatic factor as a predictor of these experiences highlights the need, and shows the urgency of overcoming symptomatic frameworks to build more individualized explanations for the phenomenon of welcoming and listening to life stories in their singularity. In addition, it makes possible to predict early actions to prevent trauma in childhood as a possible protective intervention. Keywords: Mental health; Hallucinations; Epidemiologic Factors.
\end{abstract}

\section{Introdução}

Relatos de pessoas que ouviam vozes que outros não podiam ouvir estão presentes e marcados na história de forma diferente em cada tempo (Woods, 2013). Apenas após a ascensão da sociedade industrial as vozes tornaram-se constituintes de doença, e assim permaneceram até 1980 com a emergência do movimento de ouvidores de vozes iniciado por Patsy Hage (Romme \& Escher, 1997).

Patsy iniciou um caminho de ressignificação da própria experiência de vozes com o apoio de seu psiquiatra Marius Romme, identificando as vozes como uma variação no modo de ser, que não pode e nem deve ser curada, mas é uma constante (Baker, 2009). Essa perspectiva tem sido reforçada na literatura com estudos que identificam a presença de ouvidores de voz não psiquiátricos (sem vínculo com serviços de saúde mental), na população geral.

Estima-se que de 1 a 16\% da população adulta não clínica ouça vozes pelo menos uma vez ao longo da vida (Longden, Madill, \& Waterman, 2012). Em estudo envolvendo população norueguesa não-clínica encontrou-se uma prevalência de audição de vozes de $7,25 \%$, sendo que menos de um quarto deles buscaram ajuda profissional por causa das vozes (Kråkvik, Larøi, Kalhovde, Hugdahl, Kompus, Salvesen, Stiles, \& Vedul $\square$ Kjelsås, 2015).

Estudos de associação tem pontuado a existência de uma relação entre a experiência de audição de vozes e sintomatologia de Transtorno de estresse pós-traumática (TEPT), abuso infantil, ansiedade e depressão (Bortolon \& Raffard, 2018; Mccarthy-Jones, 2018). Algumas variáveis sociodemográficas também apresentam associação com ouvir vozes como idade, sexo e residência em área urbana (Varma, Wig, Phookun, Misra, Khare, Tripathi, Behere, Yoo, \& Susser, 1997).

Este artigo se propõe a fazer uma revisão integrativa da literatura acerca da audição de vozes em populações adultas não psiquiátricas e os fatores relacionados a essa experiência.

\section{Metodologia}

A revisão sistematizada resgatou artigos das bases de dados eletrônicas: Sci-Verse Scopus (Scopus); Web of Science (WoS) e PubMed; Literatura Latino Americana e do Caribe de Informação em Ciências da Saúde (LILACS). Para estabelecimento dos descritores realizou-se uma consulta prévia no DECS (Descritores em Ciência e Saúde) e no Mesh (Medical Subject Headings), encontraram-se os descritores alucinação (Hallucinations) e alucinação auditiva (Hallucinations Auditory) para experiência de audição de voz, sendo definido como: "Sensações experimentadas subjetivamente na ausência de um estímulo apropriado, mas que são consideradas pelo indivíduo como se fossem reais. Podem ter origem orgânica ou estarem associadas com transtornos mentais" (Centro Latino-Americano e do Caribe de Informação em Ciências da Saúde, 2018).

Diante dessa significação considerou-se que adotar os descritores exatos não seria adequado para o presente estudo, pois limita a compreensão da experiência de audição de voz a perspectiva sintomatológica dos transtornos mentais. Ao mesmo tempo, tem-se clareza de que algumas produções que apresentavam um referencial teórico 
dentro do escopo deste estudo podem ter sido perdidas por estarem catalogadas de acordo com descritores do DECS como "alucinação auditiva" e "esquizofrenia". Portanto, adotaram-se os termos audição de voz (voice hearing), ouvinte de vOz (voice hearer), ouvintes de voz (voice hearers) e audição de vozes (hearing voices) como estratégia de busca. A escolha destes termos se deve ao fato de serem os mais comumente utilizados pelos autores, e por possibilitarem incorporação de diferentes perspectivas teóricas no processo de resgate das publicações. Ainda, utilizou-se o operador booleano "OR" como ferramenta para o cruzamento dos termos.

Como critérios de seleção para os estudos determinou-se: ser artigo original, publicados até 2018, uma vez que esta revisão foi realizada para subsidiar a elaboração de um projeto maior acerca da experiência de audição de vozes em população adulta não psiquiátrica iniciado em 2019. Ainda, adotou-se como critérios de seleção estudos disponíveis online na íntegra nos idiomas inglês, português ou espanhol e que respondessem ao objeto da revisão. Os critérios de exclusão foram: pesquisa que adotassem os termos para se referir a problemas fonoaudiológicos, ou a ouvir as vozes das pessoas, no sentido de compreender suas demandas, relacionadas à feminismo, direitos humanos entre outras necessidades sociais, estudos realizados com crianças e adolescentes, estudos sobre a experiência de ouvir vozes realizados com pessoas que não ouvem vozes, estudos desenvolvidos apenas com população clínica (ouvidores de vozes com diagnóstico de desordem psiquiátrica).

Para a garantia da qualidade, confiabilidade e do rigor científico, os artigos oriundos da busca nas bases de dados foram submetidos à aplicação do checklist PRISMA, e avaliados por duas pesquisadoras.

\section{Resultados}

Foram resgatados 475 artigos na Scopus, 431 na WoS, 112 na PubMed e 11 na LILACS, totalizando 1029 publicações. Após leitura dos títulos e resumos, removidas as duplicações (446) e estudos indisponíveis na íntegra (1), foram aplicados os critérios de exclusão. Foram excluídos 154 por não serem estudos primários; 117 por não serem da temática "ouvidores de vozes"; 23 por adotar uma abordagem exclusivamente biomédica (eletroencefalografia, assinatura neural para alucinações, exames de imagem, abordagem farmacológica, conectividade efetiva neural de ouvidores de vozes); 25 por en- volverem apenas crianças e adolescentes; 14 por abordar validação ou, apresentação de instrumento/questionário/ guia de entrevista psiquiátricas sem dados populacionais; 1 por tratar de análise de conteúdos midiáticos sobre o tema; 2 por abordar a percepção de trabalhadores sobre audição de vozes; 1 por ser relato de caso de abordagem exclusivamente psicanalítica e 2 por se tratarem de transtornos de sono-vigília.

Dos 243 artigos sobre audição de vozes encontrados 200 foram excluídos por não abordarem prevalência e fatores relacionados à audição de vozes. Destes, 15 explanaram sobre caracterização das vozes; 22 experiências de ouvir vozes; 91 estratégias de enfrentamento às vozes; 38 sentido, significado e explicaçôes sobre as vozes; e 34 sentimento, emoção e relação com as vozes. Restaram 43 artigos elegíveis para leitura de textos completos, sendo que 25 foram excluídos por envolverem apenas população psiquiátrica. Esse processo está exibido no fluxograma de Busca (Figura 1).

Os 18 artigos selecionados para esta revisão integrativa foram publicados entre 2003 e 2018, 13 estudos transversais e cinco casos-controle. Um terço deles foram conduzidos na Inglaterra (n:4) e Estados Unidos da América (n:2). Portugal, Noruega, França, Irlanda, Escócia, Holanda, Espanha, País de Gales, Israel e China tiveram um estudo conduzido em cada. A maioria dos estudos adotou métodos não probabilísticos para seleção da amostra (n:12), nove envolveram membros da população geral, seis foram desenvolvidos com universitários, um com trabalhadores de serviços de saúde mental, um com imigrantes latinos e asiáticos nos Estados Unidos e um com ex-prisioneiros de guerra (Quadro 1).

Dos estudos analisados oito adotaram a Escala Launary-Slade (LSHS) ou sua versão revisada (LSHS-R) como modo de verificação do fenômeno de audição de vozes na população estudada (Alderson-Day, McCarthy-Jones, Bedford, Collins, Dunne, Rooke, \& Fernyhough, 2014; Berry, Fleming, Wong, \& Bucci, 2018; Bortolon, Seille, \& Raffard, 2017; Bortolon \& Raffard, 2018; Castiajo \& Pinheiro, 2017; Kråkvik et al., 2015; Preti, Sisti, Rocchi., Siddi, Cella, Masala, Petretto, \& Carta, M.G, 2014; So, Begemann, Gong, \& Sommer, 2016). Essa é uma escala auto aplicada composta por 12 questões com resposta tipo Likert de 1 a 4, com pontuações que variam de 12 a 48, quanto maior a pontuação maior a predisposição a alucinações (Launay \& Slade, 1981).

Três estudos utilizaram a Escalas de Avaliação de Sintomas Psicóticos [PSYRATS] (Andrew, Gray, \& Snow- 
den, 2008; Fleming \& Martin, 2009; So et al., 2016), um instrumento composto por 17 itens, classificados de zero a quatro em duas subescalas (delírios e alucinações) que geralmente é adotado com populações clínicas (Haddock, McCarron, Tarrier, \& Faragher, 1999), mas nesses estudos envolveu também populações não psiquiátricas.

Três estudos adotaram o Composite International Diagnostic Interview [WHO-CIDI] (BAK, Myin-Germeys, Delespaul, Vollebergh, De Graaf, \& VanOs, 2005; Devylder, Oh, Yang, Cabassa, Chen, \& Lukens, 2013; Gomez \& Freyd, 2017)., instrumento desenvolvido na década de 80 pela Organização Mundial de Saúde (WHO) para possibilitar estudos de caráter internacional no âmbito da saúde mental. É composto por 288 perguntas sobre sintomas, com respostas dicotômicas distribuídas em 15 seções, com uma específica para esquizofrenia e outras desordens psicóticas (Kessler \& Üstün, 2004)., compondo o bloco de questões sobre experiências incomuns, como ter visões ou ouvir vozes que outros não podem ouvir (Quintana, Gastal, Jorge, Miranda, \& Andreoli, 2007).-

Os demais estudos valeram-se do Manual Diagnóstico e Estatístico de Transtornos Mentais III revisado [DSM III-R] (Bak et al., 2005), do Psychosis Screening Questionnaire [PSQ] (Alsawy, Wood, Taylor, \& Morrison, 2015), da Escala de Alucinação revisada [RHS] (Morrison \& Petersen, 2003), da Escala de avaliação do sintoma [SCL90R] (Crompton, Lahav, \& Solomon, 2017) do Computerized Diagnostic Interview Schedule [C DIS$-I V]$ (Landin-Romero, R, McKenna, P.J., Romaguera, A., Alvarez-Moya, E., Sarro, S., Aguirre, C., Sarri, C., Compte, A., Bosque, C., Salvador, R., \& Pomarol-Clotet, E., 2016) para rastreio. 


\section{"voice hearing" OR "voice hearer" OR "voice hearers" OR "hearing voices"}

Scopus
475 publicações

WoS
431 publicações
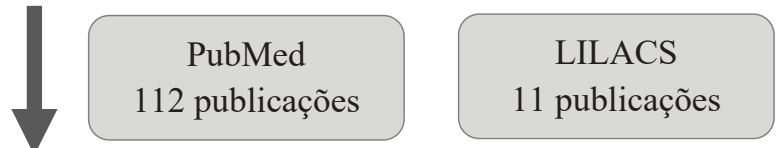

1029 títulos e resumos

154 não eram estudos primários

117 foram excluídos por não serem da temática "ouvidores de vozes"

- anestesiologia (1), estudos com animais (1), artes (5), avaliação de serviço (3), diálogo interno (1), economia (3), educação (6), espiritualidade (2), experiência de presença contínua (1), filosofia (1), fonoaudiologia (17), história (3), Justiça (6), Literatura (3), marketing (1), métodos de pesquisa (4), movimento feminista (4), organizações participativas em saúde mental (1), parapsicologia (1), política de participação social (3), robótica (2), Simulações, induções ou experiências análogas à audição de vozes Audição de Vozes (21), Síndromes genéticas e orgânicas (8), Psicose e uso de SPA (4), suicídio (3), Outros transtornos mentais (12).
128 foram excluídos por relacionar-se a:

- Caracterização das vozes (15);

- Experiências de ouvir vozes (22);

- Estratégias de enfrentamento às vozes (91)
446 duplicados;

1 indisponível na integra

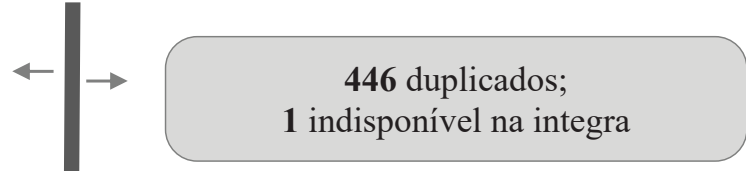

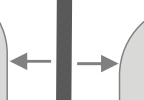

\section{8 foram excluídos por:}

- 23 por ter uma abordagem exclusivamente biomédica (eletroencefalografia, assinatura neural para alucinações; exames de imagem, abordagem farmacológica, conectividade efetiva neural de ouvidores de vozes);

- 25 por serem realizados apenas com crianças e/ou adolescentes;

- 14 por abordar validação, apresentação de instrumento/questionários/guias de entrevista sem dados populacionais;

- 1 por se tratar de análise de conteúdos midiáticos;

- 2 por abordar a percepção de profissionais acerca da AV;

- 1 por se tratar de um relato de caso de abordagem psicanalítica;

- 2 por relacionar-se à transtornos do sonovigília;
72 foram excluídos por abordarem:

- Sentido, significado, explicações sobre as vozes (38);

- Sentimento, emoção, relação com as vozes (34)

43 textos completos

- 25 Foram excluídos por se tratar de estudos de prevalência envolvendo apenas população clínica (ouvidores de vozes com diagnóstico de desordem psiquiátrica)

\section{8 artigos selecionados}

Figura 1 - Fluxograma de busca

Fonte: Elaborado pelas autoras. 


\begin{tabular}{|c|c|c|c|c|c|c|c|}
\hline & $\frac{1}{0}$ & 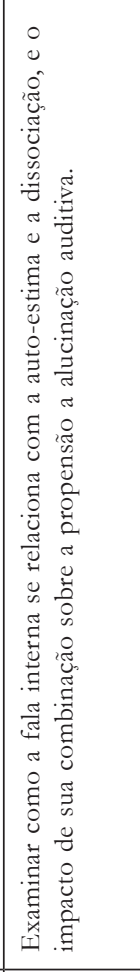 & 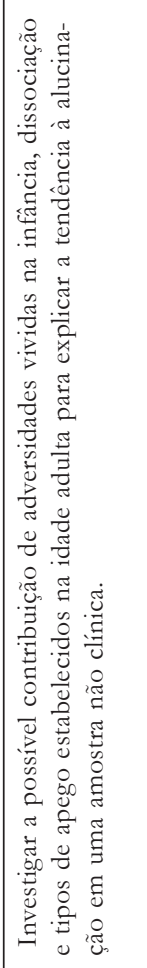 & 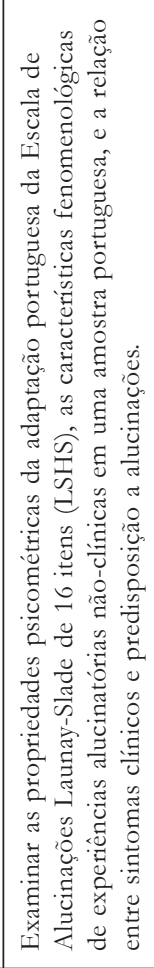 & 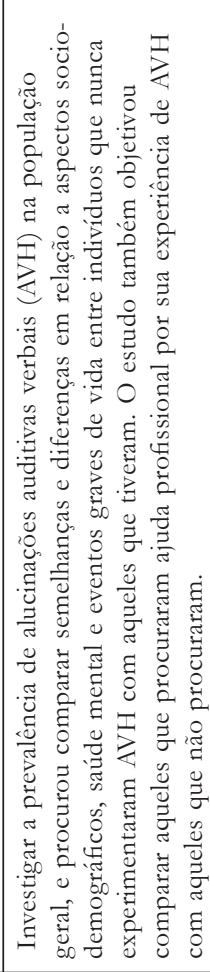 & 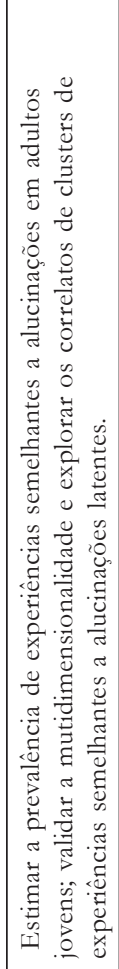 & 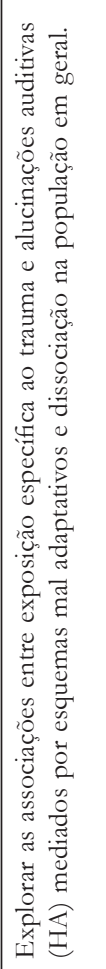 \\
\hline 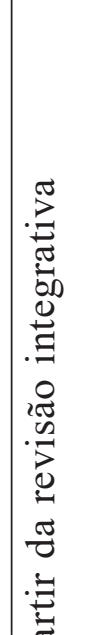 & $\frac{5}{3}$ & 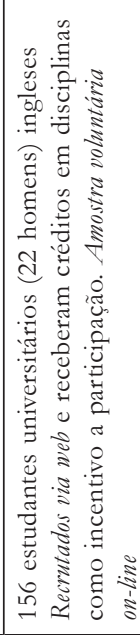 & 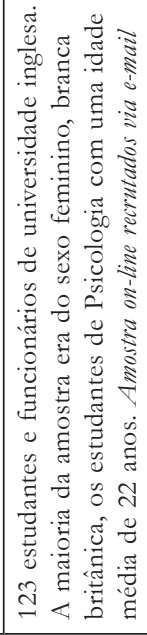 & 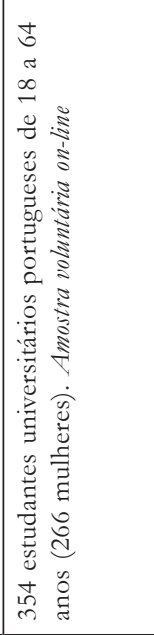 & 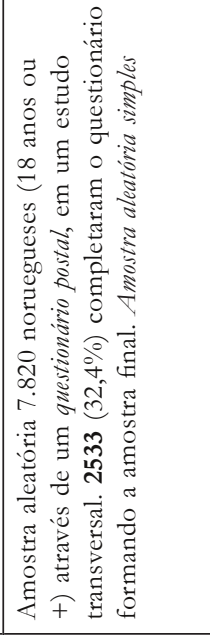 & 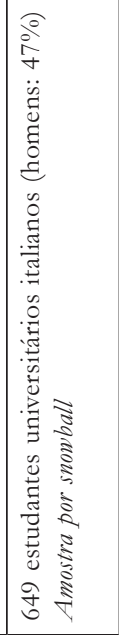 & 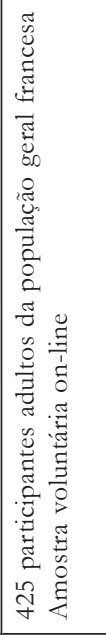 \\
\hline 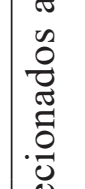 & 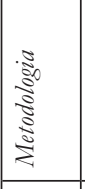 & 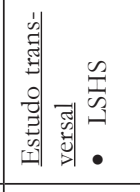 & 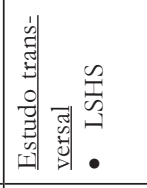 & 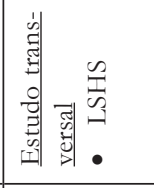 & 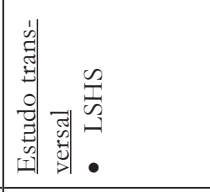 & 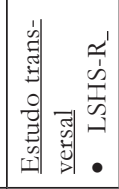 & 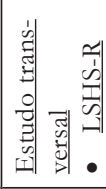 \\
\hline 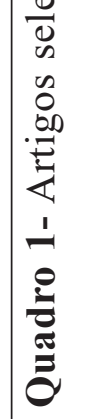 & 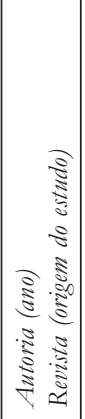 & 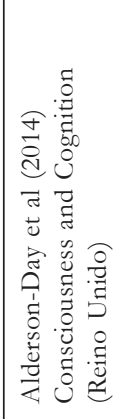 & 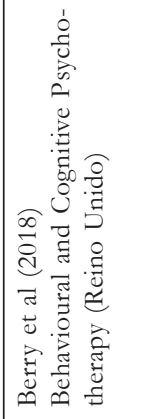 & 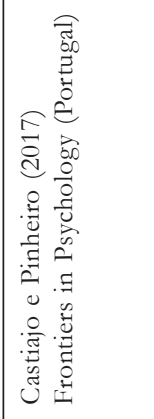 & 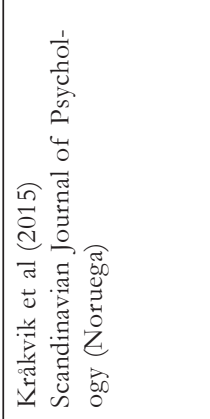 & 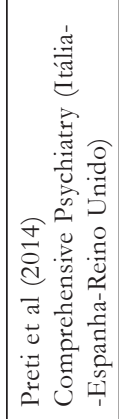 & 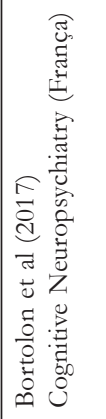 \\
\hline
\end{tabular}




\begin{tabular}{|c|c|c|c|c|c|c|c|c|c|}
\hline 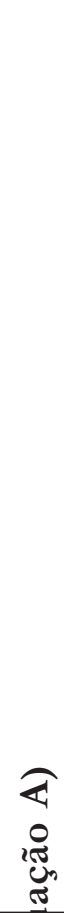 & $\frac{3}{3}$ & 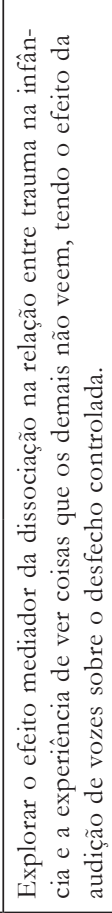 & 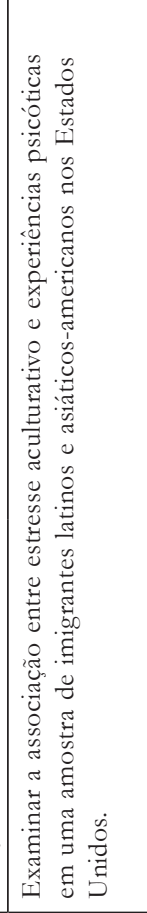 & 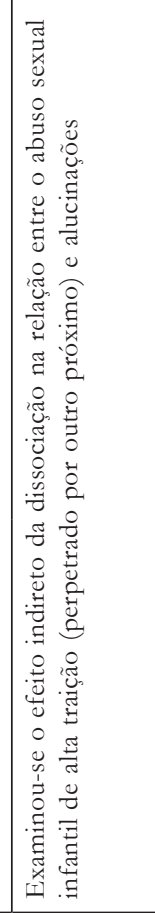 & 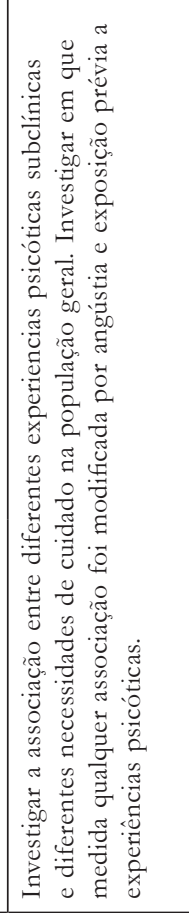 & & 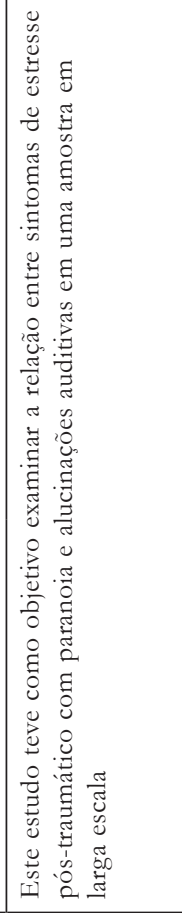 & 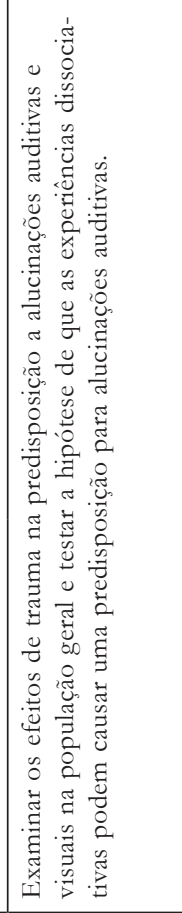 & 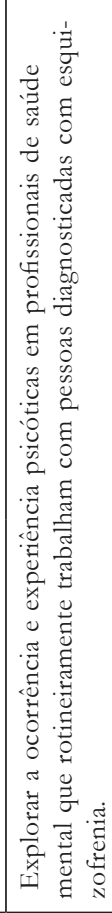 \\
\hline 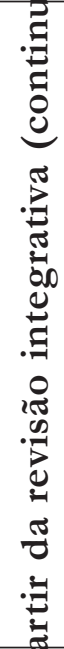 & 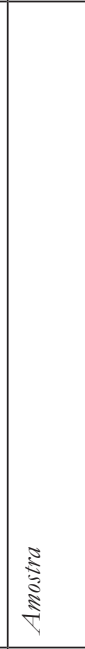 & 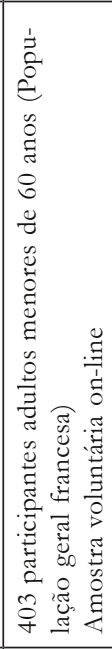 & 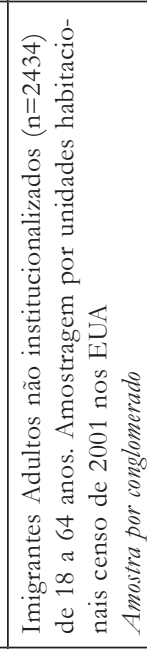 & 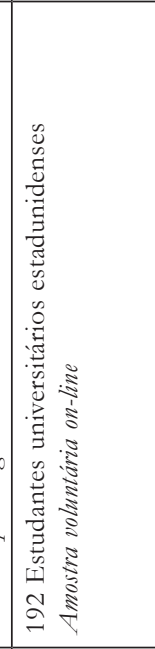 & 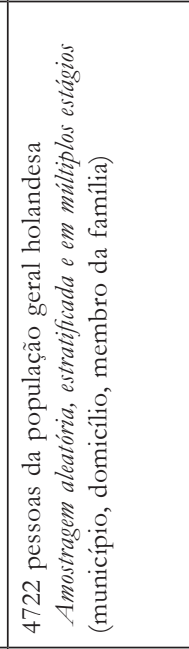 & & 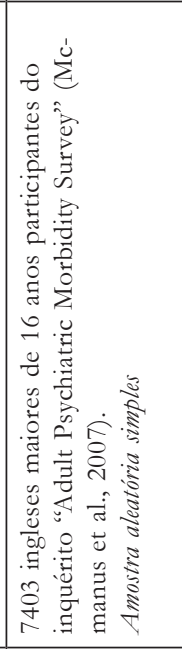 & 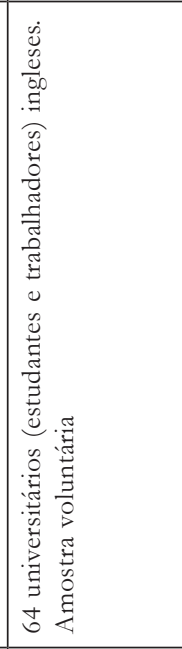 & 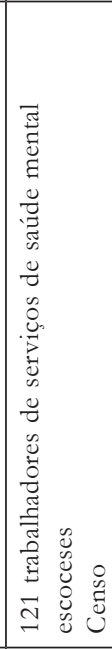 \\
\hline $\begin{array}{l}0 \\
0 \\
0 \\
0 \\
0 \\
0 \\
0 \\
0 \\
0\end{array}$ & 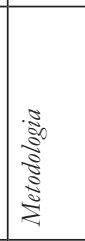 & 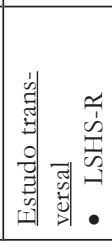 & 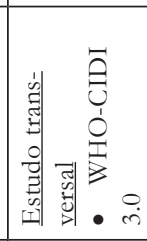 & 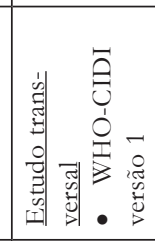 & 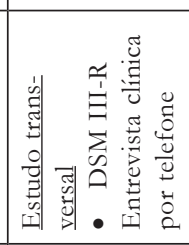 & 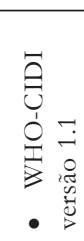 & 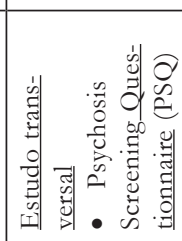 & 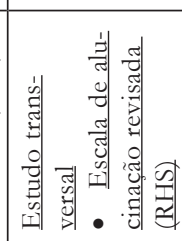 & 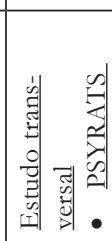 \\
\hline 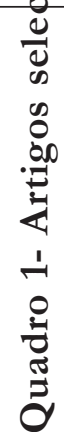 & 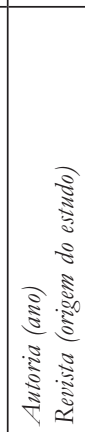 & 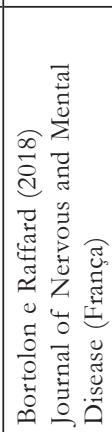 & 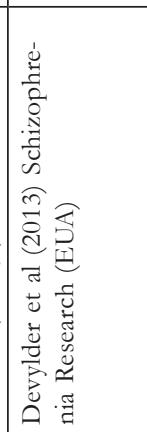 & 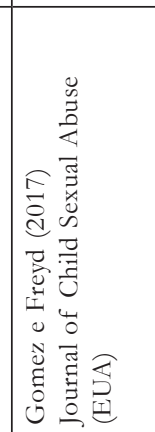 & 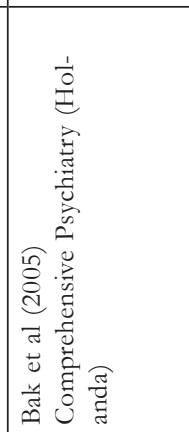 & & 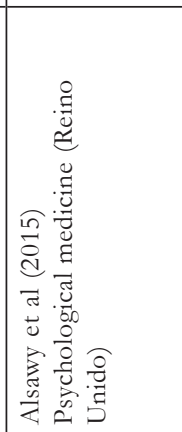 & 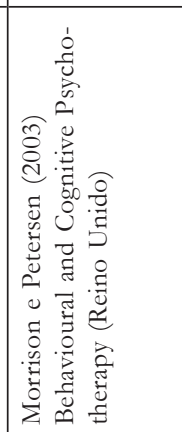 & 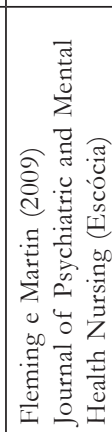 \\
\hline
\end{tabular}




\begin{tabular}{|c|c|c|c|c|c|c|}
\hline & 产 & 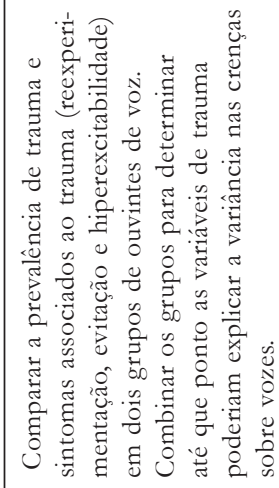 & 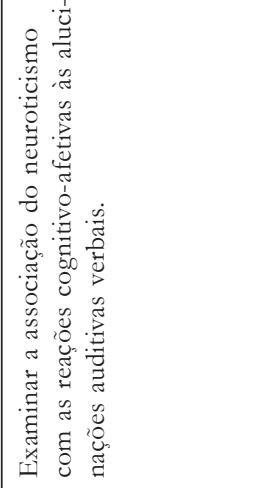 & 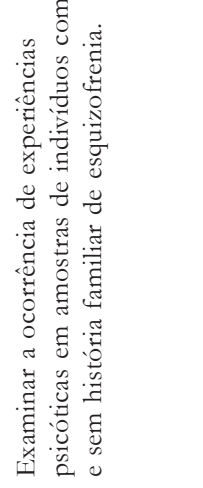 & 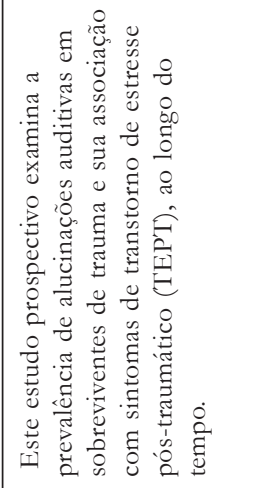 & 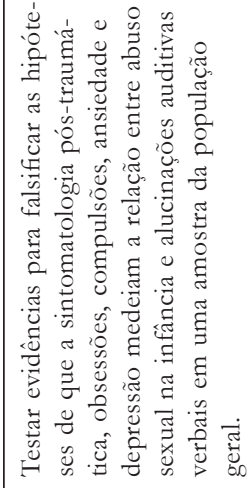 \\
\hline$\widetilde{n}$ & है & 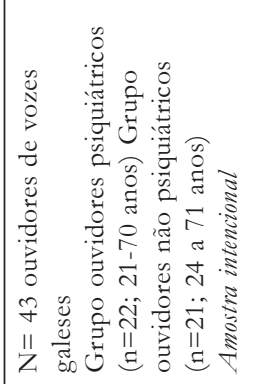 & 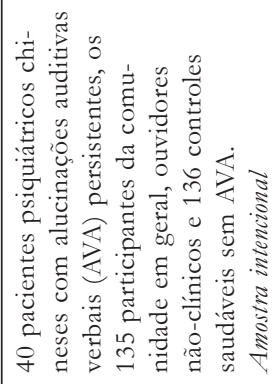 & 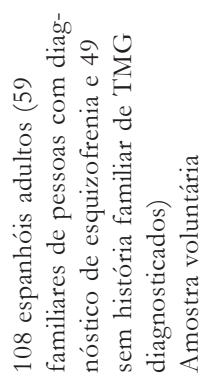 & 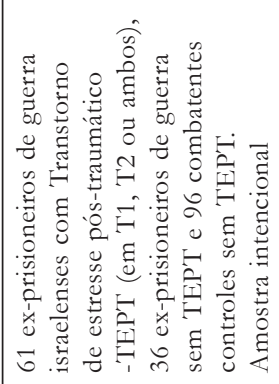 & 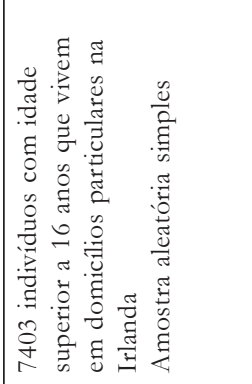 \\
\hline 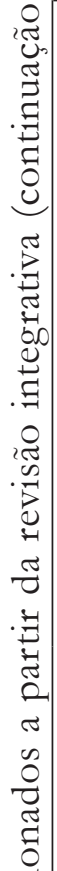 & 部 & 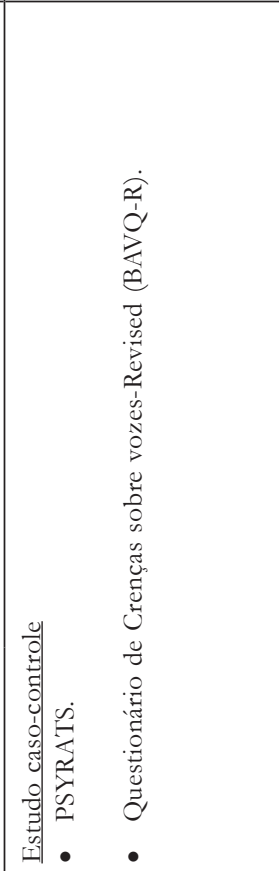 & 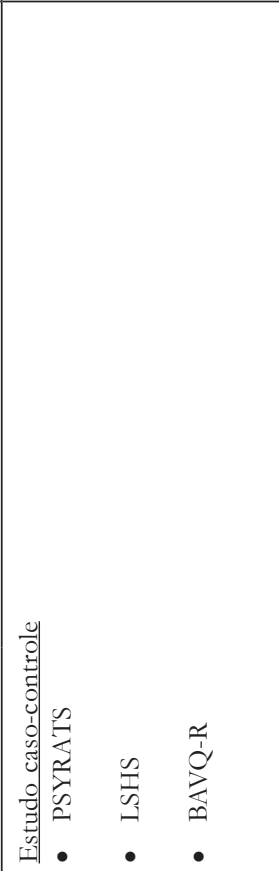 & 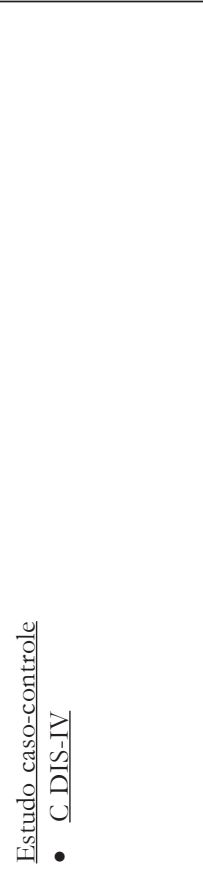 & 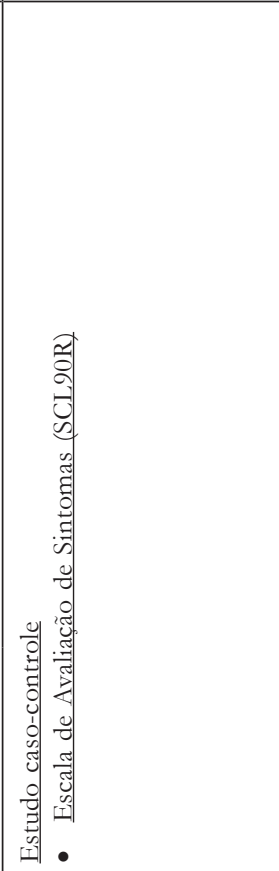 & 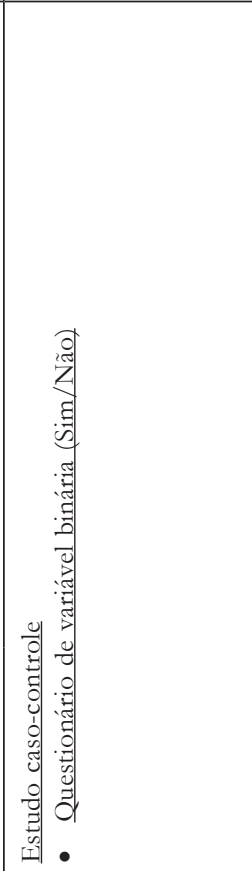 \\
\hline 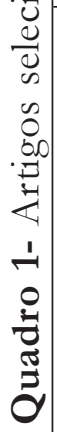 & 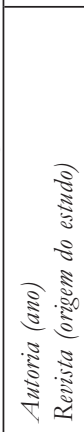 & 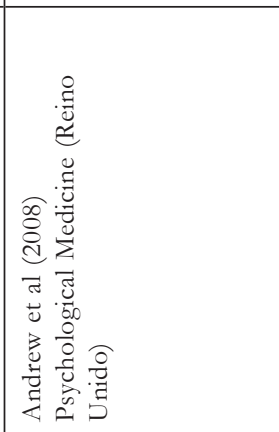 & 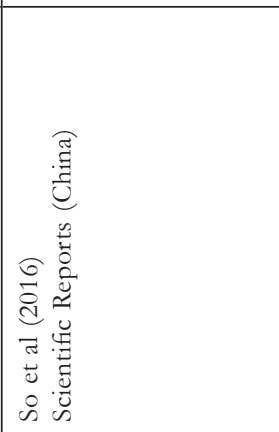 & 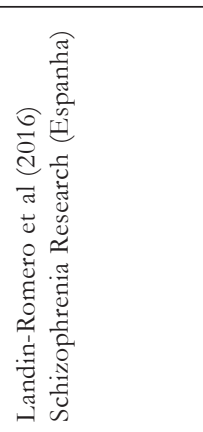 & 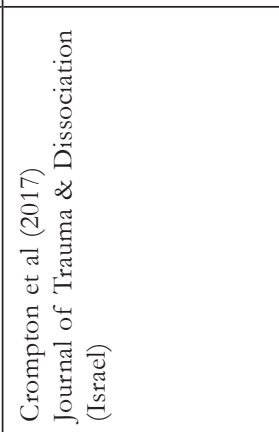 & 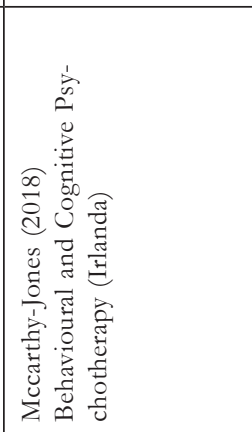 \\
\hline
\end{tabular}


Apenas um dos estudos optou por incluir um questionário de variável binária (sim/não) para autopercepção sobre a experiência de "ouvir vozes" obtida pela indagação: "(Over the past year) Did you at any time hear voices saying quite a fewwords or sentences when there was no one around that might account for it??' [Durante o ano passado/ você a qualquer momento ouviu vozes dizendo algumas palavras ou frases quando não havia ninguém por perto que pudesse explicar isso?] (Mccarthy-Jones, 2018).

Os estudos conduzidos realizaram análises multivariadas para verificação do desfecho, apontaram possíveis fatores relacionados e variáveis de mediação para experiência de audição de vozes. Deste modo, os dados serão discutidos em categoria única que versa sobre a raz̃ão de chance, razão de prevalência e os fatores relacionados a experiência de audição de vozes encontrada na literatura.

\section{Discussão}

Razão de chance, Razão de prevalência e fatores associados a experiência de ouvir vozes.

A experiência de audição de vozes apresenta-se em um continuum entre quadros clínicos e não clínicos. Vários estudos têm demonstrado que a condição de ouvir vozes não se limita a uma sintomatologia de transtornos mentais, podendo se apresentar em frequências variáveis em populações não psiquiátricas, de acordo com o modo de investigação da experiência ou a composição da amostra do estudo.

Pesquisas que adotaram a escala Launay-Slade (LSHS) ou sua versão revisada LSHS-R (Alderson-Day et al., 2014; Preti et al., 2014; Kråkvik et al., 2015; Castiajo \& Pinheiro, 2017; Berry et al., 2018; Bortolon \& Raffard, 2018) para investigar experiências tipo psicóticas em populações não clínicas vem demonstrando uma ocorrência de experiência de vozes entre 2,2 (Preti et al., 2014) a 31\% (Bortolon \& Raffard, 2018). Nesta escala a dimensão da audição de vozes é avaliada através dos itens: "In the past, I have had the experience of hearing a person's voice and then found that no onewas there" [No passado, tive a experiência de ouvir a voz de uma pessoa e depois descobri que não havia ninguém lá]"; "I often hear a voice speaking my thoughts aloud" [Muitas vezes ouço uma voz falando meus pensamentos em voz alta]'; e "I have been troubled by hearing voices in my head" [Eu tenho sido incomodado por ouvir vozes na minha cabeça] ${ }^{c}$ (Launay \& Slade, 1981).

Populações não clínicas universitárias foram envolvidas em quatros estudos que adotaram a escala LSHS
(Preti et al., 2014; Castiajo e Pinheiro, 2017; Alderson-Day et al., 2014; Berry et al., 2018). O primeiro, desenvolvido com 649 universitários italianos através da técnica snowball, encontrou uma taxa de propensão a alucinação de $11 \%$ na amostra. Aproximadamente $9 \%$ endossou com certeza a experiência do tipo " $a$ " e cerca de $2 \%$ as experiencias do tipo " $b$ " ou " $c$ " (Preti et al., 2014).

O segundo foi realizado com 354 estudantes portugueses recrutados via e-mail e investigou diferentes tipos de alucinações. Em relação às experiências alucinatórias $10 \%$ da amostra responderam como "possivelmente ou definitivamente se aplica a mim”. As alucinações auditivas apresentaram maior prevalência na amostra (13\%), seguida das olfativas $(11 \%)$, táteis $(10 \%)$ e visuais $(6 \%)$ (Castiajo \& Pinheiro, 2017).

No terceiro estudo sobre propensão a alucinações auditivas (AA), envolvendo 156 estudantes universitários no Reino Unido recrutados via web, encontrou uma média para alucinações visuais de 9.13 (DP 2.67, 5-16) na amostra (Alderson-Day et al., 2014). E, no quarto estudo, observou-se uma média de 14.76 (DP 7.8) para alucinações em uma amostra composta por 123 funcionários e estudantes recrutados através de anúncios em cartazes fixados em um campus universitário do Reino Unido (Berry et al., 2018).

Esses quatro estudos adotaram amostragem não probabilística, o que pode ter limitado o alcance do estudo, omitindo as vozes daqueles que não se voluntariaram a participação do estudo ou não compunham a rede de afetos que possibilitaria sua indicação.

Outros dois estudos envolveram populações adultas recrutadas da população geral, porém com modos de composição da amostra distintos (Kråkvik et al., 2015; Bortolon \& Raffard, 2018). Um realizou uma amostra aleatória envolvendo 7820 indivíduos cadastrados no serviço de estatística da Noruega acessados via postal, com taxa de resposta de 23\% (2533 pessoas). A pesquisa investigou a ocorrência de audição de vozes na população e a busca de ajuda profissional relacionada as vozes. Foi encontrada uma prevalência de alucinações auditivas, pelo menos uma vez ao longo da vida, de 7,3\% (IC 95\% $=6,16-8,35)$ e $2,77 \%$ das pessoas referiu ouvir vozes uma vez ao ano pelo menos (Kråkvik et al., 2015). O outro acessou por mídias sociais e sites on-line, 403 pessoas $(82 \%$ mulheres) em uma população adulta francesa, e encontrou uma percentagem de $31 \%$ para audição de vozes e $21,6 \%$ para visões, com correlação significativa 
entre as duas experiências (Bortolon \& Raffard, 2018).

Essas evidencias apontaram para uma variação na frequência de experiência de vozes entre adultos não psiquiátricos, a qual pode estar relacionada a seleção da amostra ou aos instrumentos de mensuração adotados. Em relação aos fatores relacionados a audição de vozes os estudos investigaram níveis de ansiedade, depressão e trauma na infância, em especial abuso sexual potenciais.

Em estudo com população adulta francesa não psiquiátrica verificou-se que participantes que relataram sentir-se ansiosos e deprimidos pontuaram mais sobre a experiência de ter visões, quando comparado com aqueles que negaram ansiedade e depressão. A presença de ansiedade, depressão e uso de medicações psiquiátricas nesta amostra foi de 39, 20,3 e 13,6 \%, respectivamente (Bortolon \& Raffard, 2018).

No estudo italiano envolvendo universitários encontrou metade a amostra que apresentou níveis significativamente mais elevados de propensão alucinação apresentou concomitantemente níveis altos de angústia psicológica. Isto sugere que viver experiências semelhantes a alucinação pode ou não estar vinculado ao sofrimento psíquico (Preti et al., 2014).

Em estudo com estudantes universitários portugueses, verificou-se que aqueles participantes que pontuaram mais na escala de alucinações também apresentaram maior pontuação em relação a ansiedade, sintomas depressivos e tendências esquizotípicas. As alucinações do tipo auditivas foram referidas como mais frequentes e de menor controle da experiência que as demais. O conteúdo afetivo da experiência alucinatória mostrou forte relação com a percepção de controle, quanto mais agradável mais controlável, tanto em cessar a experiência como em evitar que ela ocorra. Ainda, encontrou-se uma forte relação entre a frequência da experiência e o conteúdo afetivo agradável, sugerindo que experiências mais frequentes tendem a ser descritas como mais agradáveis (Castiajo \& Pinheiro, 2017).

Em outro estudo com universitários desenvolvido na Inglaterra observou-se que tanto a dissociação, como a fala interna condensada, ou a presença de outras vozes na fala interna demonstram efeito positivo direto na propensão a alucinações auditivas. Também que, o discurso interno avaliativo e o discurso interno com vozes de outras pessoas apresentam efeitos positivos indiretos, para propensão de alucinações auditivas, via dissociação (Alderson-Day et al., 2014). Explorar variedades de experiências de discurso interno, poderia ajudar a explicar como experiên- cias cotidianas de discurso interno podem tornar-se um acontecimento extraordinário na vida das pessoas, uma vez que suas diferentes características parecem afetar a autoestima, a dissociação e a propensão à alucinação.

Em estudo similar envolvendo estudantes e funcionários de uma universidade inglesa identificou que participantes com maiores escores de dissociação e aqueles com maiores pontuações nas escalas de apego inseguro no adulto, de ansiedade e evitação, também eram mais propensos a alucinações. A evitação, quando outras variáveis preditoras ou variáveis potencialmente confundidoras são controladas, mostrou-se um preditor independente significativo de tendência à alucinação. Também, aqueles que relataram mais eventos adversos na infância eram mais propensos a alucinações. Deste modo, os autores sugerem que experiências de trauma na infância aumentam a vulnerabilidade às alucinações, levando ao rompimento do sistema de fixação e o desenvolvimento de estados dissociativos subsequentes em resposta ao estresse (Berry et al., 2018).

E, aproximadamente $84 \%$ das pessoas que referiram ouvir vozes negaram ter procurado ajuda profissional para lidar com essa experiência (Kråkvik et al., 2015). Este achado evidencia que existem pessoas que ouvem vozes e encontraram outros modos de enfrentar a experiência de vozes que não a psiquiatria tradicional.

Também, ao fazer a análise de grupos encontrou um média de pontuação na Escala de Ansiedade de Depressão Hospitalar (HADS) maior entre os ouvidores que buscaram ajuda profissional (PH) em relação aos que não buscaram (NPH), e de ambos em relação aqueles que negaram a experiência de ouvir vozes (NAVH). Indivíduos dos grupos positivos para audição de vozes ( $\mathrm{PH}$ e $\mathrm{NPH}$ ), eram mais propensos a consultar um profissional de saúde e a usar medicações para problemas de saúde mental além dos relacionados à audição de vozes (Kråkvik et al., 2015). Esses resultados podem sinalizar uma relação direta entre o endosso a audição de vozes e a inclinação profissional para adoção medicamento como recurso para o enfrentamento dos problemas de saúde mental dessa população. Além disso, o estudo dá pistas de que o motivador para busca por profissional possa estar vinculado ao modo como a pessoa se sente diante da experiência e não, necessariamente, ao fato dela ouvir vozes.

Esse pressuposto já foi apontado em estudo neozelandês sobre o conteúdo das vozes e o trabalho com as vozes angustiante, o qual observou que ouvir vozes de 
conteúdo negativo aumenta significativamente a probabilidade do ouvidor ter respostas emocionais negativas a experiência, e ir em busca de ajuda profissional para lidar com ela. Neste estudo, verificou-se ainda que pessoas que tiveram essa resposta emocional, relataram mais vozes que assumiam os pensamentos do ouvinte, falavam por períodos mais logos e apresentavam menor possibilidade de controle, sendo mais prejudiciais ao contato com outras pessoas. No entanto, encontrou que $46,1 \%$ dos ouvidores incluídos referiam suas vozes como úteis e de conteúdo amigável e 13,6\% principalmente neutras (Beavan \& Read, 2010). Assim, destaca-se mais uma vez que a experiência de vozes é singular e sua repercussão na vida do ouvidor depende do conteúdo das vozes e da relação afetiva que o ouvidor estabelece com elas.

Um estudo holandês (Bak et al., 2005) investigou necessidades de cuidados associada a experiências tipo psicóticas subclínicas na população geral. A necessidade de cuidados foi definida como "presença de gravidade e comprometimento funcional" obtida pelo escore de nível patológico da escala Brief Psychiatric Rating Scale (BPRS) (Lukoff, Liberman, \& Nuechterlein, 1986) e consenso clínico (4 psicólogos ou psiquiatras, definem como "provável necessidade de cuidado"). Das 4722 pessoas com idade entre 18 e 64 anos, sem diagnostico prévio de desordem psicótica 191 foram elegíveis por apresentar pelo menos 1 sintoma psicótico (4\%) no WHO-CIDI 1.1, e 142 concluíram a reentrevista clínica por telefone, seguindo o DSM-III-R. Nesta amostra, 83 pessoas apresentaram pelo menos uma experiência psicótica após reentrevista, destes 59 participantes $(71,1 \%)$ não apresentaram necessidades de cuidado (Bak et al., 2005).

O estudo analisou ainda os escores de angústia/ sofrimento relacionado aos sintomas tipo psicóticos e verificou-se que dos 28 participantes que referiram ouvir vozes67,68\% negou angústia ou sofrimento com a experiência. Quando considerado outras formas de alucinações $41,9 \%$ (62) das pessoas que relataram esse tipo de experiências apresentaram maiores escores de sofrimento. Todas as experiências psicóticas se mostraram fortemente associadas a necessidade de cuidados. Mas, a associação entre necessidade de cuidados e alucinações não verbais foi grandemente reduzida após o ajuste para o sofrimento, indicando um importante papel do sofrimento como mediador, o que não foi verificado no caso das alucinações verbais (Bak et al., 2005). Isto poderia sugerir que audição de vozes é menos angustiante quando comparadas com outras formas de alucinação.

Em estudo norueguês que investigou experiências de audição de vozes, eventos traumáticos prévios e necessidade de cuidados verificou-se que os indivíduos dos grupos positivos para audição de vozes (PH e NPH), relataram números mais altos de diferentes tipos de eventos traumáticos na vida, quando comparados aqueles que não ouviam vozes (Kråkvik et al, 2015). Tal resultado anuncia que histórico de eventos traumáticos na vida pode interferir negativamente na experiência de quem ouve vozes, intensificando a necessidade de cuidados.

A literatura tem associado fortemente o fenômeno da audição de vozes à existência de eventos traumáticos, os quais tem sido apontados como possíveis preditores dessa experiência (Morrison \& Petersen, 2003; Andrew et al., 2008; Alsawy et al., 2015 ; So et al., 2016 ; Bortolon et al., 2017; Gomez \& Freyd, 2017; Berry et al., 2018; Bortolon \& Raffard, 2018; Mccarthy-Jones, 2018). Os efeitos do trauma na predisposição para alucinação auditiva e visual na população geral, foi observado em uma amostra composta por 64 sujeitos não clínicos. Evidenciou-se uma a associação significativa entre medidas relacionadas a traumas, como ideias negativas sobre o mundo, dissociação, despersonalização, amnésia dissociativa, e uma predisposição para alucinações auditivas e visuais (Morrison \& Petersen, 2003).

Alguns tipos de eventos traumáticos, como luto, agressão física e abuso emocional, se mostraram como os maiores preditores de alucinação auditiva, assim como o bullying se mostrou o maior preditor de alucinação visual. Além disso, a frequência de sintomas de TEPT e a experiência de múltiplos traumas estavam relacionados com predisposição para alucinações auditivas (Morrison \& Petersen, 2003). Esses resultados sugerem uma relação entre trauma e predisposição para alucinação auditiva e visual.

O estudo galês dedicou-se a investigar de que forma eventos traumáticos se relacionam com as crenças sobre as vozes e problemas associados a isso. Para tanto, a pesquisa comparou os diferentes tipos de trauma, prevalências e sequelas psicológicas associadas, em dois grupos de ouvidores de vozes: ouvidores usuários de serviço de saúde mental com uma predominância de crenças negativas sobre as vozes, e ouvidores não usuários com predominância de crenças positivas. Encontrou-se uma alta percentagem $(>75 \%)$ de participantes com 
pelo menos um evento traumático em ambos os grupos. Contudo, o grupo de ouvidores usuários de serviço de saúde mental apresentou sintomas de trauma suficientes para um diagnóstico de TEPT, bem como um histórico maior de abuso sexual na infância. Com isso, os autores concluíram que os eventos traumáticos vivenciados, além de serem possíveis preditores de audição de vozes, possuem grande influência nas crenças dos ouvidores sobre suas vozes (Andrew et al. 2008).

Ao contrário dos demais o estudo chinês, já partiu do pressuposto de que eventos traumáticos vivenciados na infância seriam preditores de audição de vozes, e investigou-se se o nível de neuroticismo estaria mediando as associações entre traumas na infância e as reações cognitivas-afetivas em relação às vozes (So et al., 2016). O neuroticismo é apresentado pelos autores do estudo como um traço de personalidade caracterizado por instabilidade emocional e propensão a experienciar ansiedade, medo e tristeza.

A pesquisa chinesa foi realizada com três grupos de participantes: 40 pacientes psiquiátricos com audição de vozes persistente, 135 pessoas da comunidade em geral com audição de vozes persistente e grupo controle, composto por 126 pessoas que não ouviam vozes. O estudo evidenciou que eventos traumáticos na infância tem relação com a forma que o indivíduo responde cognitivamente e afetivamente à experiência de ouvir vozes. Essa associação se mostrou mais significativa quando o trauma se tratava de abuso emocional e físico, bem como para negligência emocional e física. Portanto, segundo os autores, todos os efeitos de experiências traumáticas na infância sobre as reações emocionais às vozes, foram mediados pelo neuroticismo (So et al., 2016).

Como já constatado nos estudos anteriores (Andrew et al.,2008; So et al., 2016), o abuso sexual na infância foi um dos eventos traumáticos que levou a uma maior predisposição à audição de vozes. Por esse motivo, tem sido objeto de estudo de diversas pesquisas (Gomez e Freyd, 2017; Mccarthy-Jones, 2018). No estudo norte americano, foi investigado se a relação entre abuso sexual de alta traição na infância (quando ele ocorre no contexto de relacionamentos íntimos) e alucinações poderiam ser explicados através da dissociação. Segundo os autores, esse tipo de trauma, envolvendo traição, é diferente de outros tipos de abuso, visto que envolve maiores níveis de confiança e dependência da criança em relação ao abusador (Gomez \& Freyd, 2017).
Para responder ao objetivo do estudo 192 estudantes de uma universidade dos Estados Unidos completaram escalas autoaplicáveis pela internet, as quais investigavam histórico de abuso sexual de alta traição na infância e a presença de dissociação e alucinação no momento presente. Foi verificado $10 \%$ de abuso sexual infantil de alta traição, 41\% de alucinações e $89 \%$ de dissociação na amostra. Ao contrário do paradigma dominante, que entende a dissociação como o resultado do meio ambiente e a alucinação como um distúrbio cerebral, os resultados do estudo sugerem que essas experiências devem ser compreendidas como reações naturais ao dano inerente do abuso sexual cometido por pessoas próximas na infância. Essa nova perspectiva possibilita pensar em outras formas de cuidado para as pessoas vítimas de trauma que sofrem com dissociação e alucinação, que possam ir além da medicação e da estimulação magnética transcraniana, muito utilizadas ainda hoje (Gomez \& Freyd, 2017).

Já no estudo irlandês foi investigado se sintomas de estresse pós-traumático e pensamentos obsessivos seriam mediadores da relação entre abuso sexual na infância e alucinação verbal auditiva na população geral. O estudo utilizou dados de uma pesquisa realizada em 2007, chamada "Adult Psychiatric Morbidity Survey", a qual contou com uma amostra de 7403 indivíduos com mais de 16 anos. Foram realizadas entrevistas e aplicados questionários no domicílio, os quais abordavam dados demográficos, saúde física, saúde mental, capital social e abuso na infância. A proporção na amostra de alucinações auditivas verbais foi de $0,8 \%$, de abuso físico infantil (violência física) foi 3,6\%, e de abuso sexual infantil (com sexual relação) foi 2,2\% (Mccarthy-Jones, 2018).

Como resultado, obteve-se que apenas a sintomatologia de estresse pós-traumático sustentou-se como mediadora da relação entre abuso sexual na infância e alucinação verbal auditiva. Esse achado possibilita uma reflexão sobre a hipótese de que a alucinação verbal auditiva deveria ser um sintoma característico de TEPT (Mccarthy-Jones, 2018). Ambos os estudos (Mccarthy-Jones, 2018; Gomez \& Freyd, 2017) reiteram com seus resultados a necessidade de se investigar possíveis experiências adversas na infância e a presença de sintomas de estresse pós-traumático em pessoas com alucinação verbal auditiva.

O TEPT associado à alucinação verbal auditiva, também tem sido objeto de investigação de outras pesquisas (Alsawy et al., 2015 ; Crompton et al., 2017). O 
estudo israelense verificou a prevalência de alucinações auditivas em sobreviventes de trauma e sua associação com sintomas de TEPT ao longo do tempo. Para tanto, foram avaliados 61 ex-prisioneiros da Guerra do Yom Kippur de 1973 com TEPT, 36 sem TEPT e um grupo controle composto por 96 veteranos que não haviam sido submetidos ao cativeiro. A presença de alucinações auditivas nos grupos foi de $36,1 \%, 5,6 \%$ e $3,1 \%$, respectivamente. Essa avaliação tinha o objetivo de investigar a relação entre alucinações auditivas e sintomas de TEPT, e foi realizada em dois momentos: a primeira em 1991 (T1) e a segunda em 2003 (T2) (Crompton et al., 2017). Os resultados indicaram que ex-prisioneiros de guerra que sofreram de TEPT relataram níveis mais elevados de alucinações auditivas em T2, bem como o aumento de alucinações ao longo do tempo, em comparação com ex-prisioneiros de guerra sem TEP'T e combatentes que não foram submetidos ao cativeiro. A relação entre TEPT e alucinações auditivas foi unidirecional, pois o escore total do TEPT em T1 predisse um aumento nas alucinações auditivas entre T1 e T2, mas não vice-versa, sugerindo que alucinações auditivas podem ser uma consequência da reação pós-traumática entre os veteranos (Crompton et al., 2017).

$\mathrm{O}$ estudo inglês também examinou a relação entre sintomas de TEPT e alucinação auditiva utilizando como banco os dados da pesquisa "Adult Psychiatric Morbidity Survey". Encontrou-se que $78 \%$ das pessoas que experimentaram alucinações auditivas também tiveram trauma. Os resultados mostraram quanto maior a quantidade de sintomas de TEPT, maior a probabilidade de desenvolver alucinações auditivas, sugerindo uma relação dose-resposta (Alsawy et al., 2015)

O papel da dissociação na relação entre o trauma e as alucinações auditivas também têm sido investigada na literatura. Dois estudos envolveram população geral francesa em suas investigações sobre o tema (Bortolon et al., 2017; Bortolon \& Raffard, 2018) e um envolveu população universitária inglesa (Berry et al., 2018), todos através de instrumento de coleta on-line.

Para de explorar o papel de esquemas mal adaptativos e dissociação como mediadores da relação entre trauma e alucinação auditiva um dos estudos (Bortolon et al., 2017) incluiu 425 participantes da população geral francesa em um inquérito on-line sobre trauma. Os autores do estudo entendem os esquemas como sendo a forma como cada indivíduo percebe a si mesmo, e a sua relação com os outros. Nesse sentido, experiências traumáticas na infância podem levar ao desenvolvimento de esquemas mal adaptativos, prejudicando a forma como os indivíduos percebem, pensam e comportam-se no mundo. Entre os participantes, 12,4\% estavam em uso de medicação psiquiátrica 19,0\% apresentavam sintomas de depressão e $37,0 \%$ de ansiedade.

Os resultados apontam que abuso sexual e emocional impactam na alucinação auditiva, ambos através do efeito de esquemas mal adaptativos e dissociação; abuso físico impacta na alucinação auditiva somente através dos efeitos da dissociação; e que quatro tipos de esquemas, mais especificamente, impactam na alucinação auditiva, são eles: abandono, vulnerabilidade, sacrifício pessoal e subjugação (Bortolon et al., 2017). É possível entender a partir disso que exista uma relação bastante forte entre dissociação e esquemas mal adaptativos com traumas vivenciados na infância e alucinação auditiva, o que reforça a necessidade de se investigar esses esquemas como uma forma terapêutica de trabalhar com pessoas que ouvem vozes.

Em outro estudo partiu-se da mesma amostra francesa do estudo anterior (425 pessoas), excluindo-se aqueles com mais de sessenta anos de idade, o que resultou em uma amostra de 403 pessoas. Neste estudo, explorou-se o efeito mediador da dissociação na sua relação entre o trauma na infância e visões, tendo controlado o efeito da audição de vozes sobre o desfecho "visões". O principal resultado encontrado pelos autores foi que a dissociação, como um mecanismo de defesa, mediou a relação entre trauma na infância e a experiência de ver coisas que os outros não podem ver (Bortolon e Raffard, 2018).

Por fim, o estudo inglês corroborou com os achados dos estudos anteriores, pois encontrou que as pessoas que vivenciam eventos traumáticos na infância estavam mais propensas à alucinação auditiva, bem como as que sofreram de dissociação em algum momento da vida, e as que possuíam vínculos inseguros com as outras pessoas. Contudo, os autores não encontraram associações significativas entre abuso físico e sexual e propensão para alucinação auditiva neste estudo. Eles acreditam que isso esteja relacionado a composição da amostra, estudantes de psicologia com poucos relatos de vivência de abuso Independentemente deste aspecto, evidenciou-se, assim como nos demais estudos, que tanto a dissociação, como formas de se relacionar com os outros, baseado em vín- 
culos inseguros são mecanismos que estão envolvidos na propensão à alucinação auditiva (Berry et al., 2017).

Outra pesquisa envolvendo imigrantes latinos e asiáticos nos Estados Unidos que teve o Composite International Diagnostic Interview-CIDI (Kessler \& Üstün, 2004) como instrumento de investigação, observou que o estresse aculturativo vivenciado pelos imigrantes pode ser um promissor candidato para explicar a relação entre imigração e psicose (Devylder et al., 2013).

Foi encontrado uma prevalência aproximada de $7 \%$ para fenômenos psicóticos entre 2434 imigrantes adultos não institucionalizados, mas quando considerada apenas a experiência de "ouvir vožes que os outros não podem ouvir", a prevalência entre latinos e asiáticos foi de 4,0 e 2,5\%, respectivamente. Aqueles que sinalizaram positivamente para itens relacionados à estresse aculturativo apresentaram maior probabilidade de ouvir vozes, em especial entre os asiáticos. Entre os entrevistados latinos, quanto mais jovem a idade de imigração maior foi o risco para qualquer experiência psicótica, especificamente alucinações visuais e auditivas. Os resultados sugerem que seria possível reduzir o risco de psicose entre imigrantes realizando intervenções para minimizar o estresse relacionado ao processo de imigração (Devylder et al., 2013).

Estudos investigando outras relações possíveis para experiências semelhantes a alucinações como histórico familiar de esquizofrenia (Landin-Romero et al., 2016) e indução de sintomas por proximidade terapêutica (Fleming \& Martin, 2009), também foram desenvolvidos, abordando populações específicas não psiquiátricas. No estudo tipo caso-controle realizado com 108 adultos, 59 com história familiar e 49 sem histórico familiar de esquizofrenia verificou-se um endosso positivo de 36\% para questões de psicose presentes no C DIS-IV, não havendo diferença significativa entre os grupos. Ao verificar o item sobre alucinações auditivas, na amostra, apenas 1 participante do estudo referiu ter experimentado o sintoma, por um período limitado e um ambiente restrito, com ruídos (Landin-Romero et al., 2016).

Outro estudo explorou sintomas psicóticos em profissionais de saúde mental que trabalham diretamente com pessoas diagnosticadas com esquizofrenia (Fleming \& Martin, 2009). Para isso, entrevistou 121 trabalhadores de serviços de saúde mental do Reino Unido utilizando a PSYRATS (Haddock et al., 1999), escala que visa obter detalhes específicos acerca das diferentes dimensões de alucinações auditivas. Como resultado, verificou-se uma presença de 16\% de experiências de alucinações auditivas na amostra, apresentando uma correlação significativa com maiores escores de ansiedade (Fleming \& Martin, 2009).

Os estudos analisados nessa revisão demonstraram que de 0,8\% (Landin-Romero et al., 2016) a 41\% (Gomez \& Freyd, 2017) das pessoas estudadas referiram positivamente para experiências tipo psicóticas dependendo da amostra e do instrumento utilizado. As escalas adotadas para mensuração do fenômeno, embora validadas, podem trazem consigo variações acerca do constructo social da experiência de ouvir vozes, o que resultaria em uma dificuldade conceitual para determinação do fenômeno. Ainda, embora alguns estudos tenham analisado itens específicos das escalas avaliativas para identificação do tipo de sintoma psicótico (ouvir vozes, ter visões ou sensações), a literatura mostra que esse tipo de experiência extraordinária é complexa e, por vezes, coexistente com outros grupos de sintomas (Bortolon \& Raffard, 2018).

Para o movimento de ouvidores de vozes a separação da experiência não deve se dar em sintomas isolados. As vozes estão ligadas ao fenômeno do sentir, e assim, podem sem sentidas de diversas formas. Podem ser ouvidas (dentro ou fora da cabeça), presas ou não aos ouvidos. Podem vir de partes do corpo sendo comunicadas pela respiração, por odores, ou por sensações táteis e visões (Coleman \& Smith, 2009). Adotar o termo "ouvir vozes" para descrever essa gama de experiencia traz como vantagem o fato de ser um termo neutro, reconhecido e utilizado popularmente, desvencilhado do significado patologizante produzido pelo termo "alucinação" (Baker, 2009, 2016).

Destaca-se que é preciso saber que diferentes perspectivas sobre as vozes trazem consigo diferentes explicações e definições. Tanto as histórias de vida dos pacientes como as dos não-pacientes estão repletas daquilo que chamamos traumas existenciais. Mas, o que é fundamental compreender a diferença entre os ouvidores que conseguem e os que não conseguem se entender com suas vozes, pois de certo modo, é isso que poderá torná-los pacientes psiquiátricos ou não (Romme \& Escher, 1997).

A partir do exposto, entende-se que a audição de vozes, assim como outras experiências ditas psicóticas são vivenciadas por muitas pessoas, com intensidades, frequências e repercussões diferentes na vida de cada ouvidor. A presença marcante na literatura do fator traumático como preditor dessas experiências ressalta a 
necessidade de acolhimento e escuta das histórias de vida em sua singularidade. E, evidencia a urgência da superação dos enquadramentos sintomáticos para construção de explicações mais individualizadas para o fenômeno. Além disso, possibilita vislumbrar ações precoces para prevenção de trauma na infância como possível intervenção protetora.

\section{Considerações finais}

Este estudo revisou a literatura em busca de conhecer como a audição de vozes se apresenta em populações não psiquiátricas e os fatores relacionados a essa experiência. No que tange a distribuição do fenômeno, embora se espere uma prevalência aproximada de $10 \%$ na população, foi possível identificar uma variação significativa de acordo com as estratégias de mensuração do fenômeno e amostragem, o que evidencia a necessidade de novos estudos populacionais sobre essa temática.

A literatura incluída nessa revisão relacionou a experiencia "ouvir vozes" a altos níveis de ansiedade, depressão, angústia psicológica e tendências esquizotípicas. Embora dois terços das pessoas que vivem a experiência neguem sofrimento relacionado a ela, a existência dele foi fortemente associado a necessidade de cuidados. Apresentar sofrimento frente a experiencia de ouvir vozes torna a pessoa mais propensa a consultar um profissional de saúde, e fazer uso de psicofármacos além dos relacionados à audição de vozes.

Também encontrou entre os ouvidores de vozes maiores pontuações nas escalas de trauma na infância, dissociação, apego inseguro no adulto e evitação. Houve ainda, a identificação de que ouvidores vinculados aos serviços de saúde mental tem maior probabilidade de ter histórico de abuso sexual na infância e de apresentar sintomas de TEPT. Os eventos traumáticos que se mostraram como preditores da experiência de "vozes" foram: abuso sexual na infância, agressão física e abuso emocional, luto, bullying e estresse aculturativo.

Verificou-se ainda, a partir da literatura, que os efeitos das experiências traumáticas na infância sobre a predisposição a audição de vozes apareceram mediados por neuroticismo, dissociação, esquemas mal adaptativos e sintomatologia de TEPT. Ainda, identificou-se que quanto mais sintomas de TEPT a pessoa apresentar maior será sua probabilidade de ouvir vozes.

\section{Referências}

Alderson-Day, B., McCarthy-Jones, S., Bedford, S., Collins, H., Dunne, H., Rooke, C., Fernyhough, C. (2014). Shot through with voices: Dissociation mediates the relationship between varieties of inner spe ech and auditory hallucination proneness. Consciousness and Cognition, 27(1), 288-96.

Alsawy, S., Wood, L., Taylor, P.J., \& Morrison, A.P. (2015). Psychotic experiences and PTSD: exploring associations in a population survey. Psychological Medicine, 45(13), 2849-59.

Andrew, E.M., Gray, N.S., \& Snowden, R.J. (2008). The relationship between trauma and b eliefs about hearing voices: A study of psychiatric and nonpsychiatric voice hearers. Psychological Medicine, 38(10), 1409-17.

Bak, M., Myin-Germeys, I., Delespaul, P., Vollebergh, W., De Graaf, R., \& VanOs, J. (2005). Do different psychotic experiences differentially predict need for care in the general population? Comprehensive Psychiatry, 46(3), 192-9.

Baker, P. (2016). Abordagem de Ouvir Vozes: Treinamento Brasil. Marília, SP: CENAT - Centro Educacional Novas Abordagens Terapêuticas.

Baker P. (2009). The voice inside: a practical guide for and abaut people who hear voice. Isle of Lewis: P\&P.

Beavan, V., Read, J. (2010). Hearing voices and listening to what they say: The importance of voice content in understanding and working with distressing voices. Journal of Ne rvous and Mental Disease, 198(3), 201-5.

Berry, K., Fleming, P., Wong, S., \& Bucci, S. (2018). Associations between Trauma, Dissociation, Adult Attachment and Proneness to Hallucinations. Behavioural and Cognitive Psychotherapy, 46(3), 292-301.

Bortolon, C., \& Raffard, S. (2018). Dissociation Mediates the Relationship between Childhood Trauma and Experiences of Seeing Visions in a French Sample. Journal of Nervous and Mental Disease, 206(11), 850-8.

Bortolon, C., Seille J., \& Raffard, S. (2017). Exploration of trauma, dissociation, maladaptive schemas and auditory hallucinations in a French sample. Cognitive Neuropsychiatry, 22(6), 468-85.

Castiajo, P., \& Pinheiro, A.P. (2017). On "hearing" voices and "seeing" things: Probing hallucination predisposition in a Portuguese nonclinical sample with the Launay-Slade Hallucination Scale-revised. Frontiers in Psychology, 8(jul), 1-17.

Centro Latino-Americano e do Caribe de Informação em Ciências da Saúde [BIREME/OPAS/OMS]. (2019). Descritores em Ciências da Saúde: DeCS. São Paulo. Recuperado em: https://pesquisa.bvsalud.org/portal/ decs-locator/?lang=pt

Coleman, R., Smith, M. (2009). Lavorare con le voci. IV ed. Torino: EGA; 75 p.

Crompton, L., Lahav, Y., Solomon, Z. (2017). Auditory hallucinations and PTSD in ex-pows. Journal of Trauma \& Dissociation, 18(5), 663-78.

DeVylder, J.E., Oh, H.Y., Yang, L.H., Cabassa, L.J., Chen, F.P., \& Lukens, E.P. (2013). Acculturative stress and psychotic-like experiences among Asian and L atino immigrants to the United States. Schizophrenia Research, 150(1), 223-8.

Fleming, M.P., \& Martin, C.R. (2009). A preliminary investigation into the experience of symptoms of psychosis in mental health professionals: Implications for the psychiatric classification model of schizophrenia. Journal of Psychiatric and Mental Health Nursing, 16(5), 473-80.

Gomez, J.M., \& Freyd, J.J. (2017). High Betrayal Child Sexual Abuse and Hallucinations: A Test of an Indirect Effect of Dissociation. Journal of Child Sexual Abuse, 26(5), 507-18.

Haddock, G., McCarron, J., Tarrier, N., \& Faragher, E.B. (1999). Scales to measure dimensions of hallucinations and delusions: the psychotic symptom rating scales (PSYRATS). Psychol Med, 29(4), 879-89.

Kessler, R.C., \& Üstün TB. (2004). The World Mental Health (WMH) survey initiative version of the World Health Organization (WHO) Composite International Diagnostic Interview (CIDI). International Journal of Methods in Psychiatric Research, 13(2), 93-121.

Kråkvik, B., Larøi, F., Kalhovde, A. M., Hugdahl, K., Kompus, K., Salvesen, Ø., Stiles, T.C, \& Vedul $\square$ Kjelsås, E. (2015). Prevalence of auditory verbal hallucinations in a general population: A group comparison study. Scandinavian Journal of Psychology, 56(5), 508-5015.

Landin-Romero, R, McKenna, P.J., Romaguera, A., Alvarez-Moya, E., Sarro, S., Aguirre, C., Sarri, C., Compte, A., Bosque, C., Salvador, R., \& Pomarol- 
Clotet, E. (2016). Examining the continuum of psychosis: Frequency and characteristics of psychotic-like symptoms in relatives and non-relatives of patients with schizophrenia. Schizophrenia Research, 178, 6-11.

Launay, G., Slade, P. (1981).The measurement of hallucinatory predisposition in male and female prisoners. Personal Individ Differ, 2, 221-34.

Longden, E., Madill, A., \& Waterman, M.G. (2012). Dissociation, trauma, and the role of lived experience: toward a new conceptualization of voice hearing. Psychological Bulletin, 138(1), 28-76.

Lukoff, D., Liberman, R.P., \& Nuechterlein, K.H. (1986). Symptom monitoring in the rehabilitation of schizophrenic patients. Schizophr Bull, (12), 578- 602

McCarthy-Jones, S. (2018). Post-Traumatic Symptomatology and Compulsions as Potential Mediators of the Relation between Child Sexual Abuse and Auditory Verbal Hallucinations. Behavioural and Cognitive Psychotherapy, 46(3), 318-31.

Morrison, A.P., \& Petersen, T. (2003). Trauma, metacognition an d predisposition to hallucinations in non-patients. Behavioural and Cognitive Psychotherapy, 31(3), 235-46.

Preti, A.P., Sisti, D., Rocchi, M.B.L., Siddi, S., Cella, M., Masala, C., Petretto, D.R., \& Carta, M.G. (2014) Prevalence and dimensionality of hallucinationlike experiences in young adults. Comprehensive Psychiatry, 55(4), 826-36.
Quintana, M.I., Gastal, F.L., Jorge, M.R., Miranda, C.T., Andreoli, S.B. (2007). Validity and limitations of the Brazilian version of the Composite International Diagnostic Interview (CIDI 2.1). J Brazilian Journal of Psychiatry, 29, 18-22.

Romme, M., \& Escher, S. (1997). Na companbia das vozes: para uma análise da experiência de ouvir vozes. Lisboa: Editorial Estampa, Lda.

So, S. H., Begemann, M.J.H., Gong, X., Sommer, I.E. (2016).Relationship between neuroticism, childhood trauma and cognitive-affective responses to auditory verbal hallucinations. Scientific Reports, 6(34401), 1-8.

Varma, V.K., Wig, N.N., Phookun, H.R., Misra, A.K., Khare, C.B., Tripathi, B.M., Behere, P.B., Yoo, E.S., \& Susser, E.S. (1997). First-onset schizophrenia in the community: Relationship of urbanization with onset, early manifestations and typology. Acta Psychiatrica Scandinavica, 96(6), 431-8.

Woods, A. (2013). The voice-hearer. J Ment Health, 22(3), 263-70.

Submetido em: 14-11-2020

Aceito em: 3-11-2021 